\title{
Development of an Advanced Recycle Filter Tank Assembly for the ISS Urine Processor Assembly
}

\author{
Dwight E. Link, Jr. ${ }^{1}$ \\ The Boeing Company, Huntsville, Alabama, 35812 \\ Donald Layne Carter ${ }^{2}$ \\ NASA Marshall Space Flight Center, Huntsville, Alabama \\ and \\ Scott Higbie ${ }^{3}$ \\ Flexial Corporation, Cookeville, Tennessee, 38502
}

\begin{abstract}
Recovering water from urine is a process that is critical to supporting larger crews for extended missions aboard the International Space Station. Urine is collected, preserved, and stored for processing into water and a concentrated brine solution that is highly toxic and must be contained to avoid exposure to the crew. The brine solution is collected in an accumulator tank, called a Recycle Filter Tank Assembly (RFTA) that must be replaced monthly and disposed in order to continue urine processing operations. In order to reduce resupply requirements, a new accumulator tank is being developed that can be emptied on orbit into existing ISS waste tanks. The new tank, called the Advanced Recycle Filter Tank Assembly (ARFTA) is a metal bellows tank that is designed to collect concentrated brine solution and empty by applying pressure to the bellows. This paper discusses the requirements and design of the ARFTA as well as integration into the urine processor assembly.
\end{abstract}

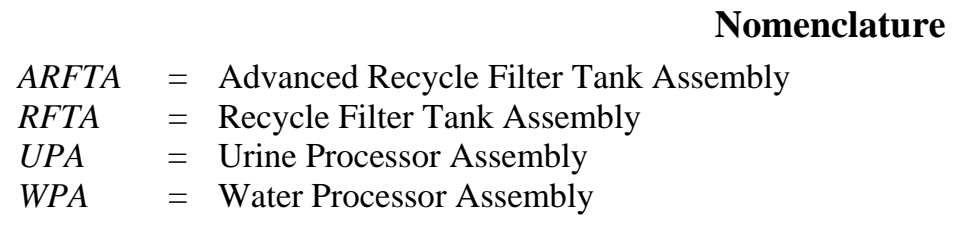

\section{Introduction}

$\mathrm{T}$ HE International Space Station (ISS) uses water recovery technology that accommodates recycling of Crew metabolic waste (humidity condensate and urine) into potable water for consumption and also for generation of oxygen. As a result, the need for resupply of water is minimized or eliminated. The systems that process and recover water for use need resources from the ISS in order to operate, which include power, command and control, and cooling. They also require resupply from the ground in order to remain in a healthy operational state. The systems utilize moving machinery (such as pumps and valves), sensors, and consumables that require regular replacement, which results in a high demand for spares.

Currently, long term operation of the ISS has driven a need to find new ways to maintain system hardware with less resupply from the ground. Most of the systems have been developed for maintenance at the orbital resupply unit (ORU) level. These ORUs include groups of components that can be replaced with minimal crew time and effort. These ORU component groupings usually result in larger packages which demand more space and up mass for spares replenishment. The Space Shuttle vehicle and pressurized logistics elements provide a large up mass and

\footnotetext{
${ }^{1}$ Mechanical Design Manager, ISS Program, 499 Boeing Blvd., PO Box 240002, M/S JS-66

${ }^{2}$ Life Support Systems Development Team Lead, ES62

${ }^{3}$ Engineering Manager, 1483 Gould Drive, P.O. Box 3105
} 
volume capacity, and the ability to manage larger amounts of resupply, however, with the retirement of the Space Shuttle fleet, the capacity for resupply is greatly reduced making it critical to minimize the resources required form the ground to maintain system operation.

The urine processing system used on ISS is a good example of the ISS resupply problem. The system used to recover water from urine results in a large volume of concentrated brine waste that must be disposed. The current hardware design uses a collection tank, called the Recycle Filter Tank Assembly (RFTA), that is returned to the ground for disposal. This method was selected to minimize the crew hazards inherent with servicing the Urine Processor Assembly (UPA). The RFTA also includes product water filters that are serviced at regular intervals with the tank, resulting in minimized crew time for UPA maintenance operations, but is less efficient in terms of resupply up mass requirements.

In order to support long term ISS operations with reduced up mass capacity, the RFTA is being modified in order to allow on orbit servicing of the system. Instead of returning concentrated brine contained in the RFTA to the ground (or disposing as trash), a new tank is being developed that is serviceable on orbit. The tank would collect the concentrated brine solution in the same fashion as the current tank, but would be removable such that it can drained into an existing disposable storage tank such as the tanks contained in the Progress module or Autonomous Transfer Vehicle (ATV). This paper will focus on the modifications to the ISS UPA as well as the details for the design of the Advanced Recycle Filter Tank Assembly (ARFTA) and associated components.

\section{ISS Urine Processor Operations}

The ISS Waste and Hygiene Compartment (WHC) collects urine and flush water that is treated with chromium trioxide and sulfuric acid to stabilize the urine and control microbial growth. The resulting mixture, identified as pretreated urine, is classified as a hazardous fluid due to the chromium and a $\mathrm{pH}$ of approximately 2.0. This pretreated urine is delivered to the UPA, where it is stored in a Wastewater Storage Tank Assembly (WSTA). A peristaltic pump removes water from the WSTA and processes it through the recycle loop, which include a Distillation Assembly (DA) and the RFTA. In the DA, water and other volatiles are evaporated under vacuum of approximately 40 torr. As the water is evaporated from the recycle loop, the remaining fluid is concentrated into a brine mixture. As water is evaporated from the loop, additional pretreated urine is fed into the recycle loop to maintain volume. This process continues until a specified recovery limit is reached. This percent recovery is based on a limit that will halt the concentration process before precipitation occurs in the recycle loop, which could damage system components. When the percent recovery is achieved, the RFTA is removed along with the concentrated brine and a new unit is installed to restart the process. The water collected from the distillation process (referred to as distillate) is filtered and delivered to the Water Processor Assembly (WPA) for additional processing into potable water.

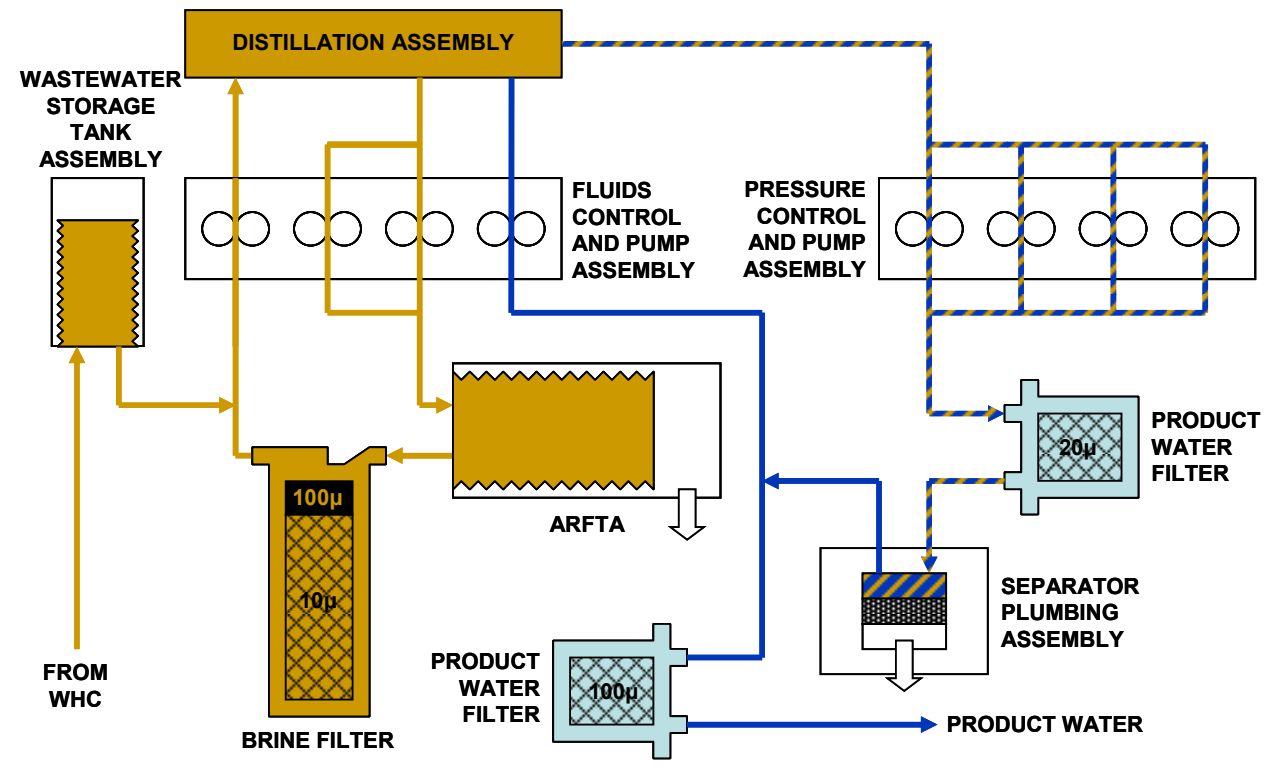

Figure 1. Urine Processor System Diagram.

American Institute of Aeronautics and Astronautics 
The UPA is being modified to replace the RFTA with the ARFTA. The filters previously contained within the RFTA ORU are relocated and will be separate components so that the ARFTA can be serviced independently. The revised UPA system diagram is shown in figure 1. System operation is not affected by this change, except the operating cycle is reduced due to the smaller system capacity. This is discussed further in the tank design section of this paper.

\section{Advance Recycle Filter Tank Assembly Requirements}

The ARFTA consists of four major components: the ARFTA bellows tank assembly, the brine filter assembly, the product water filter assembly, and the purge gas filter assembly. The requirements for these components were derived based on UPA system requirements such that operation of the system would not be impacted. A summary of the key component requirements is shown in table 1.

Table 1. ARFTA requirements summary.

\begin{tabular}{|c|c|c|c|c|}
\hline Requirement & Bellows Tank Assembly & Brine Filter & $\begin{array}{l}\text { Product Water } \\
\text { Filter }\end{array}$ & Purge Gas Filter \\
\hline Operating Fluid & Pretreated Urine & Pretreated Urine & Urine Distillate & $\begin{array}{l}\text { Urine Distillate } \\
\text { and non- } \\
\text { condensable } \\
\text { gasses }\end{array}$ \\
\hline $\mathrm{pH}$ & $1.0-2.1$ & $1.0-2.1$ & $3-5$ & $3-5$ \\
\hline Flow Rate & $\begin{array}{l}21.8 \mathrm{Kg} / \mathrm{hr} \max \\
(48 \mathrm{lb} / \mathrm{hr} \max )\end{array}$ & $\begin{array}{l}21.8 \mathrm{Kg} / \mathrm{hr} \text { max } \\
(48 \mathrm{lb} / \mathrm{hr} \max )\end{array}$ & $\begin{array}{c}10.9 \mathrm{Kg} / \mathrm{hr} \max \\
(24 \mathrm{lb} / \mathrm{hr} \max )\end{array}$ & 180 cc/min max \\
\hline Pressure Drop & $\begin{array}{l}34.5 \text { millibar } \\
(0.5 \text { psid })\end{array}$ & $\begin{array}{l}69 \text { millibar } \\
(1 \text { psid })\end{array}$ & $\begin{array}{l}69 \text { millibar } \\
(1 \text { psid })\end{array}$ & $\begin{array}{l}69 \text { millibar } \\
(1 \text { psid })\end{array}$ \\
\hline Temperature & $\begin{array}{l}18 \mathrm{C}-41 \mathrm{C} \\
(65 \mathrm{~F}-105 \mathrm{~F})\end{array}$ & $\begin{array}{l}18 \mathrm{C}-41 \mathrm{C} \\
(65 \mathrm{~F}-105 \mathrm{~F})\end{array}$ & $\begin{array}{c}16 \mathrm{C}-39 \mathrm{C} \\
(61 \mathrm{~F}-103 \mathrm{~F})\end{array}$ & $\begin{array}{c}16 \mathrm{C}-39 \mathrm{C} \\
(61 \mathrm{~F}-103 \mathrm{~F})\end{array}$ \\
\hline $\begin{array}{l}\text { Maximum Design } \\
\text { Pressure }\end{array}$ & $\begin{array}{l}1.39 \text { bar (20 psid) (urine side) } \\
0.81 \text { bar (11.8 psig) (air side) }\end{array}$ & 1.72 bar (25 psid) & 1.39 bar (20 psid) & 1.39 bar (20 psid) \\
\hline Free Gas & $<0.25 \%$ & $<0.25 \%$ & $<10 \%$ & $0-100 \%$ \\
\hline Filtration & N/A & 10 micron & 100 micron & 20 micron \\
\hline Service Life & 10 years minimum & 30 days minimum & 30 days minimum & 30 days minimum \\
\hline
\end{tabular}

The key performance requirements for the ARFTA tank design are maximizing fluid volume in the available space and maintaining a negative internal pressure to support filling operations. The design approach for modifying the UPA to integrate the ARFTA was to use the existing space allocated to the RFTA in the system rack as well as any available unused space internal to the WRS-2 Rack, and to meet the performance requirements using this space allocation. This approach resulted in a fixed external tank geometry. The ARFTA bellows tank diameter and length are essentially the same as the RFTA, however, since the bellows occupies space within the ARFTA the resulting tank capacity is reduced from 41 liters to approximately 21 liters. This translates into a reduced system operating cycle since the recycle loop will reach the percent recovery limit after processing a smaller volume of pretreated urine. Maintaining an internal negative pressure is necessary in order to draw fluid into the ARFTA during filling operations and to maintain the volume of the recycle loop during the process cycle.

Due to the corrosive nature of the pretreated urine and concentrated brine solutions, material compatibility is an additional key requirement for the ARFTA hardware. Materials of construction are limited to a list of alloys that have been tested for exposure to this fluid. The materials selected are: Alloy 625, Alloy C276, Ti CP and Ti 6AL$4 \mathrm{~V}$, Teflon, and Viton. Limiting the tank construction to these material selections will assure a minimum 10 year operational life.

Tank servicing operations add additional considerations and requirements to the tank and external support equipment design. The tank is planned to be emptied using an air compressor to pressurize the gas side of the 
bellows with up to $0.8 \mathrm{~atm}$ (11.8 psi). The external pressure must overcome the resistance of the bellows and the external plumbing to the disposal tank.

The ARFTA external filter requirements are derived from the existing RFTA components. The key constraint again is volume, and maximizing the filtration capacity within the available volume. The flow, pressure, and pressure drop are all based on existing UPA performance requirements.

\section{Advanced Recycle Filter Tank Assembly Design}

\section{A. ARFTA Bellows Tank Design}

The existing RFTA design integrates filtration components into the tank to allow for efficient removal and replacement with minimal crew time. The brine filtration is integrated into the tank, and water filters are integrated into an external housing. The ARFTA design incorporates a flexible metal bellows tank to allow for hermetic, reliable sealing of the highly corrosive concentrated brine. A valve is integrated into the front of the tank to isolate the internal volume of the bellows tank during handling, and quick disconnects and hose assemblies are added to allow for flow of solution into and out of the tank. A quick disconnect connection is also provided on the front of the tank assembly that provides access to the gas side of the bellows for servicing the tank. A comparison of the RFTA and ARFTA tank designs is illustrated in figure 2.

RFTA

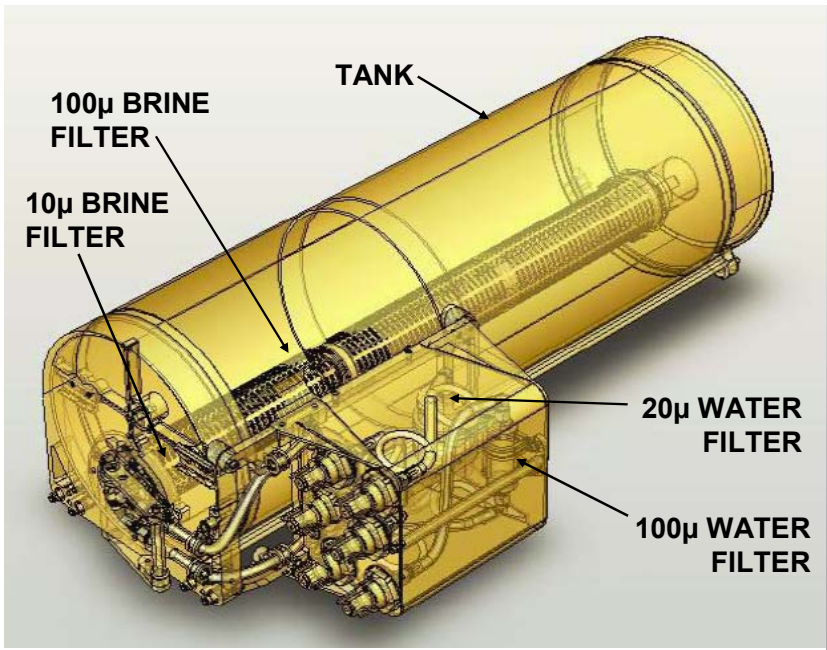

ARFTA

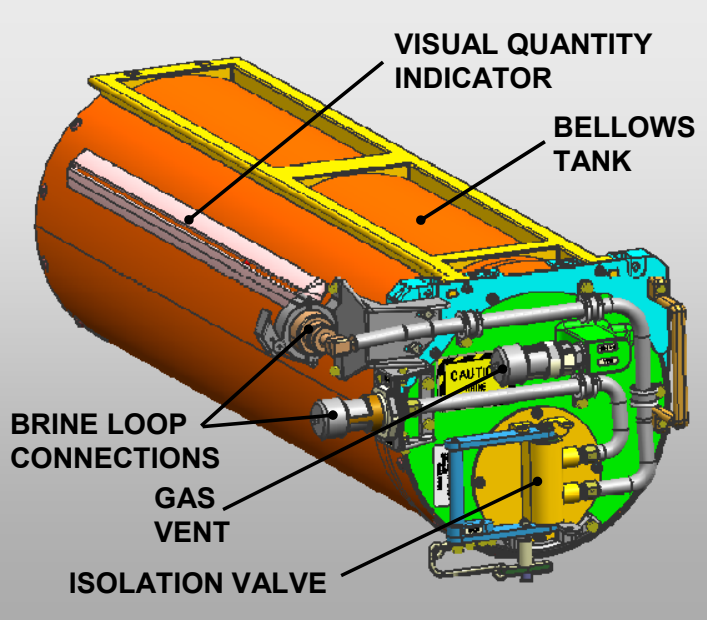

Figure 2. Urine Processor tank design comparison.

The ARFTA tank has an outside diameter of $26.7 \mathrm{~cm}$ (10.5 inches) and is $83.8 \mathrm{~cm}$ (33.0 inches) long with a fluid displacement of over 21.7 liters (1323 cubic inches). An external visual indicator provides bellows movable termination position and a tank level of percentage full for crew members to easily monitor for fluid servicing. It operates with an extremely low $\mathrm{pH}$ acid solution $(\mathrm{pH}$ 1.6) comprising part of the treatment process. Fluids are internal to the bellows in order to meet the system required negative operating pressure. Liftoff pressure of the bellows (onset of motion) is 69 millibar (1 psid) and full stroke pressure is less than 241.5 millibar (3.5 psid). This pressure differential helps the ARFTA pull fluids from UPA Wastewater Storage Tank Assembly (WSTA), and also is minimized to allow for bellows compression using the existing air compressor hardware.

The tank enclosure and bellows contour design is similar to the already in service WSTA. Since that design was successfully qualified much of the design was based on legacy data. A hybrid configuration was implemented to make much of the exterior of the structure out of titanium alloy 6AL-4V. The fluid containment is supplied by the bellows and would be wetted with the highly ionic treatment solution, but was chemically compatible with each other and with the solution. The bellows is designed with a $25.4 \mathrm{~cm}$ (9.99 inch) OD by $21.7 \mathrm{~cm}$ (8.54 inch) ID, 277 convolutions and $0.254 \mathrm{~mm}$ (0.010 inch) thick diaphragm material. For protection of the bellows from launch 
vibration, the tank engineering incorporated a patented design used in vibration and high impact applications. This involves use of heavy end convolutions applied asymmetrically to each end of the bellows to passively dampen vibration-induced waves in the convolutions. A detailed diagram of the bellows tank components is shown in figure 3.

\section{Tank Assembly}

1. Bellows Sub-Assembly

5. Housing (Titanium)

6. End Cap (Titanium)

7. Bracket (304L SS)

8. Rail (304L SS)

9. ISO Valve (Various)

10. Manifold (Titanium)

11. Clip (Alloy C-276)

\section{Bellows Sub-Assembly}

1. Bellows (Alloy C-276)

2. Stationary Term/Port Cap (Alloy C-276)

3. Sweeper (Alloy C-276)

4. Elastomeric Sweeper Guide

(majority of bellows convolutions removed for clarity)

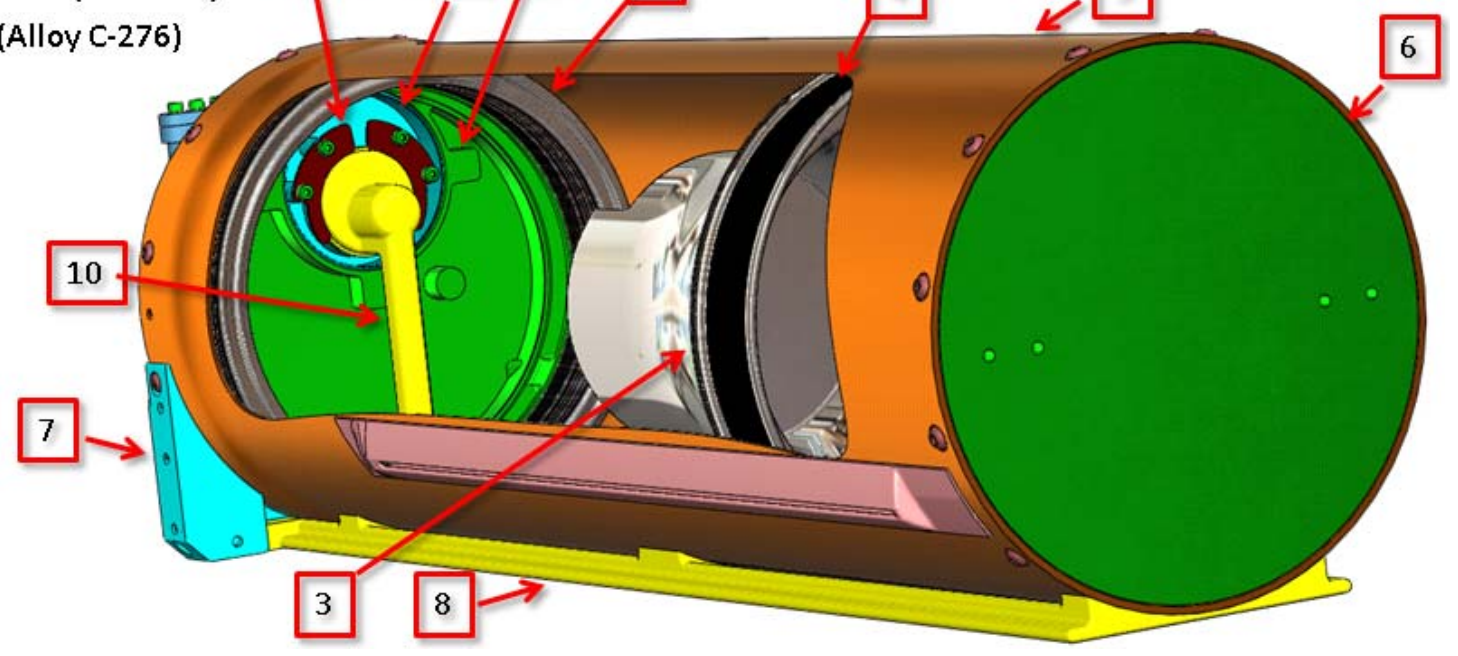

Figure 3. ARFTA bellows tank design detail.

\section{B. Fluid Mixing}

Adequate mixing of the brine in the recycle loop is critical for UPA health. A consistent concentration throughout the recycle loop is required since the process cycle time is based on recovering a set percentage of water by volume from the pretreated urine, and any localized concentration gradients could result in precipitation. The large fluid volume in the RFTA or ARFTA is a specific issue because of the risk that a short circuit in the internal flow path results in a concentration gradient. The existing RFTA design produces good mixing since the flow of solution through the tank is driven by the exit filter configuration along the length of the tank. Implementing a bellows design for the ARFTA meant that the inlet and outlet ports of the tank needed to be co-located on the front end cap of the tank. To address the mixing concern, the inlet and outlet ports were separated such that the fluid discharge into the tank volume pushed the flow path to the rear of the tank before it becomes drawn out the exit. The resulting flow velocities are sufficient to yield adequate internal mixing in the ARFTA.

\section{Hazardous Fluid Containment Approach}

Containment of the concentrated brine solution in the UPA is a key requirement for crew safety reasons. The tank must provide three sealing mechanisms for the concentrated brine solution so the resulting design is two-fault tolerant. The existing RFTA is welded permanently closed and not intended to be serviced. This was possible because of single-alloy construction. In the ARFTA hybrid design, titanium and Hastelloy are not weldable to each other. This required a bolt-up construction with o-ring sealed joints to provide the required containment. This is also preferred as it allows subsequent inspection or refurbishment. Both ends are removable, however, the bolt-up region, 
being thicker than a welded joint, presented a weight penalty. To offset this as much as possible, a radial bolt pattern was chosen for button-head bolts of alloy A286. Redundant seals at the joints, a safety hazard containment requirement, also presented a minor weight penalty but the existing design is within the weight requirement.

\section{ARFTA Filter Assembly Design}

\section{A. Brine Filter}

The UPA system includes a filter to collect any solid precipitates formed in the accumulator during distillate production. The existing RFTA incorporates this filter into the tank itself to facilitate removal and replacement. Since the ARFTA tank uses a metal bellows to draw fluid into the tank and to empty the concentrate, the filter was removed from the tank and located in a different area of the rack.

The filter element is a 10 micron absolute polypropylene microfiber pleated element, which is packaged into a titanium housing sized to fit within the available space in the rack. The filter incorporates an additional 100 micron screen that is downstream of the 10 micron element, which provides additional protection in the event of a filter failure. The housing incorporates three sealing features to provide the required two fault tolerance for leakage of the brine mixture. Fluid quick disconnects are incorporated into the end cap to provide safe and easy replacement. A diagram of the

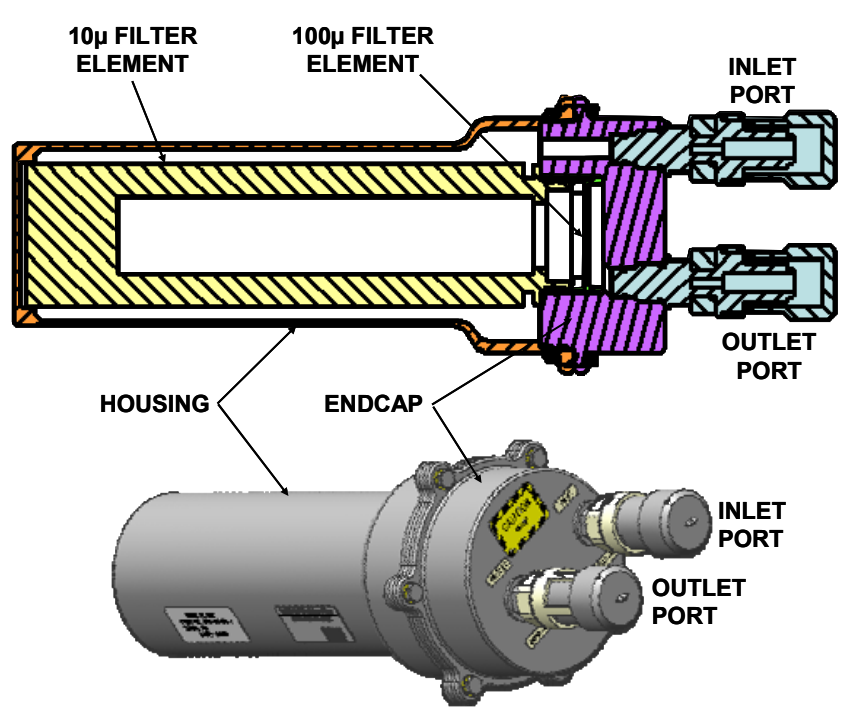

Figure 4. Brine filter assembly design detail. brine filter assembly is shown in figure 4 .

The filter life is expected to be limited by material compatibility. The current filter is certified for 60 days of exposure to the urine pretreat solution; however efforts are under consideration to perform additional testing to extend that material life.

\section{B. Urine Distillate Filters}

There are two distillate filters in the UPA system: one provides 100 micron filtration of the distillate stream, and a second that provides 20 micron filtration of the purge gas stream. These filters are currently housed in the RFTA, and as a result must be relocated external to the ARFTA bellows tank. The redesigned filter sizes are much larger with a corresponding greater capacity, primarily since there is more available space and the housing geometry is required to accommodate a standard ISS quick disconnect for the inlet and outlet connections. Flow and pressure drop are additional constraints, however the larger size is an advantage to maximize the filter capacity and increase operational life. The filter assembly envelopes are shown in Figure 5.

The filters are constructed from stainless steel housings with an internal pleated stainless steel wire mesh elements sized to 20 micron and 100 micron respectively.

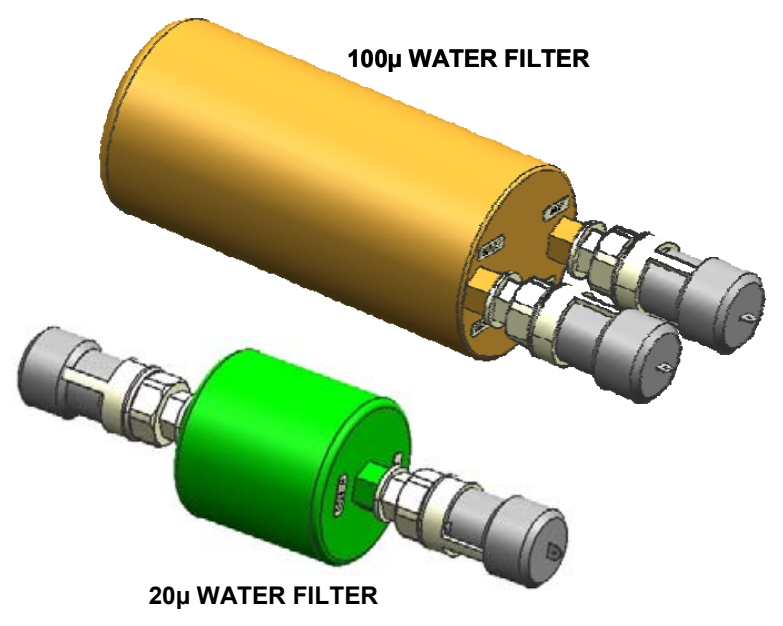

Figure 5. Urine distillate filter assembly design detail. 


\section{Advanced Recycle Filter Tank Assembly Integration into the Urine Processor Assembly}

The UPA is installed into a standard ISS equipment rack volume. The resulting system layout is densely packaged and a critical factor in executing the ARFTA modification is installing the new components in such a way that the system performance is maintained and overall maintainability of the hardware is not adversely affected. The

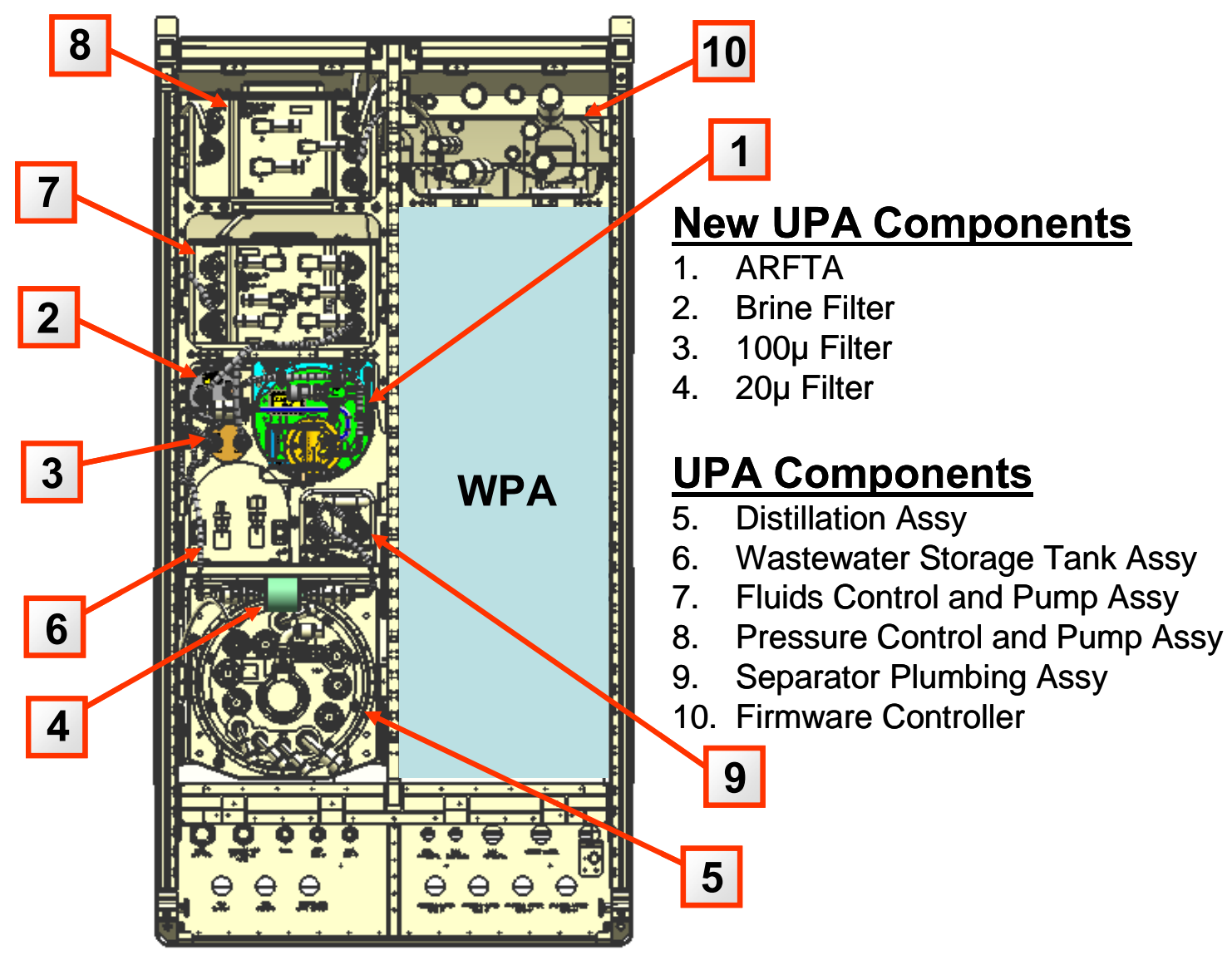

Figure 6. Revised Urine Processor Assembly layout.

approach taken was to utilize the RFTA tank envelop and mounting features for the ARFTA, and to relocate the brine filter and distillate filters external to the tank. This requires some changes to the rack distribution lines to accomplish. Figure 6 shows the revised UPA layout.

The ARFTA is slide mounted beneath the Fluids Control and Pump Assembly. The volume previously allocated for the distillate filters has now been used to accommodate the larger brine filter and the 100 micron distillate filter. The 20 micron distillate filter has been relocated to a space in front of the distillation assembly. New hoses maintain the correct connectivity throughout the system.

Flow and pressure drop analyses have been performed to verify that the system flows will not be affected by the new configuration. The bellows tank volume is $21.7 \mathrm{~L}$ (1323 cubic inches) in comparison to the RFTA which is 41 $\mathrm{L}$. The resulting maintenance schedule for the ARFTA is expected to drop significantly from approximately 21 days ( $70 \%$ recovery of urine from $3 \mathrm{crew}$ ) to approximately 11 days due to the reduction in capacity. 


\section{Conclusion}

Implementation of the new ARFTA hardware in the UPA will change the way in which the UPA is operated. Performance is not expected to be affected; however, the system will be much less dependent on resupply from the ground to operate. The capacities of the filters have been maximized within the available volume, and are expected to yield much longer life than current predictions making the system less dependent of resupply. Additional time will be required for regular maintenance of the ARFTA tank (draining and filling), but the on board crew will have the ability to maintain the system in an operational state resulting in less risk of interruption of water production.

\section{Acknowledgments}

The authors would like to acknowledge the Flexial Corporation in Cookeville, TN, for their participation in this design project. Without their expertise in this field the successful development of the ARFTA would not be possible.

In addition, the authors would like to thank Mr. Shane Norris and Mr. Patrick James of the Boeing Company for their assistance with illustrations contained within this paper. 